\title{
Comments on Modeling of Gauss Elimination Technique and AHA Simplex Algorithm for Multi-objective Linear Programming Problems by Sanjay Jain and Adarsh Mangal
}

\section{Chandra Sen}

Professor (Retired), Department of Agricultural Economics, Institute of Agricultural Sciences, Banaras Hindu University, Varanasi-221005, India.

\section{To Cite this Article}

Chandra Sen, "Comments on Modeling of Gauss Elimination Technique and AHA Simplex Algorithm for Multi-objective Linear Programming Problems by Sanjay Jain and Adarsh Mangal", International Journal for Modern Trends in Science and Technology, 6(9): 94-96, 2020.

\section{Article Info}

Received on 11-August-2020, Revised on 19-August-2020, Accepted on 29-August-2020, Published on 09-September-2020.

\section{ABSTRACT}

An excellent research contribution was made by Sanjay and Adarsh in using Gauss Elimination Technique and AHA simplex method for solving multi-objective optimization (MOO) problems. The method was applied for solving MOO problems using Chandra Sen's technique and several other averaging techniques. The formulation of multi-objective function in the averaging techniques was not perfect. The example was also not appropriate.

KEYWORDS: Gauss Elimination Technique, AHA Simplex Algorithm, Multi-Objective Optimization, Chandra Sen's MOO Technique.

\section{INTRODUCTION}

The linear programming problems can be solved using various methods. The Gauss Elimination Technique and AHA simplex method was used by Sanjay and Adarsh [1] in solving MOO problems. The method has been applied to solve an example using Chandra Sen's MOO technique [2] and other averaging techniques [3]-[18]. The multi-objective functions in the averaging techniques have not been formulated appropriately [19]-[23].

The use of example with non conflicting objectives was not appropriate.

\section{METHODOLOGICAL CONFLICTS}

Chandra Sen's MOO technique and several averaging techniques have been used for solving
MOO problems. The formulation of multi-objective function has been explained below:

\subsection{Chandra Sen's MOO Technique}

A multi-objective optimization problem may have multiple objectives of different dimensions. The combined objective function is formulated by weighting the each objective by the inverse of its optimal value. This makes the combined objective function dimensionless. The formulation of combined objective function is described below:

Maximize $Z=\frac{\sum_{j=1}^{r} Z j}{\left|\Theta_{j}\right|}-\frac{\sum_{j=r+1}^{S} Z j}{\left|\Theta_{r+1}\right|}$

Subject to:

$$
\begin{array}{lr}
A X=b & \text { and } X \geq 0 \\
\Theta_{j} \neq 0 & \text { for } J=1,2 \ldots \ldots \ldots . s .
\end{array}
$$

\section{Where,}

$\Theta_{j}$ is the optimal value of $j^{\text {th }}$ maximizing objective and $\Theta_{r+1}$ is the optimal value of $(r+1)$ th minimizing objective. 


\subsection{Averaging MOO Techniques}

The study under review has scalarized the objectives by the several averages of the optimal values of different objectives. The formulation of multi-objective function combining the values of different dimensions seems illogical. The multi-objective function has been formulated as detailed below:

$$
\begin{aligned}
& \text { Maximize } Z=\frac{\sum_{j=1}^{r} Z \mathrm{j}}{\left|\Theta_{1}\right|}-\frac{\sum_{j=r+1}^{s} Z \mathrm{j}}{\left|\Theta_{2}\right|} \\
& \text { Subject to: } \\
& \begin{array}{ll}
\mathrm{AX}=\mathrm{b} & \text { and } \mathrm{X} \geq 0 \\
\Theta_{\mathrm{j}} \neq 0 \quad \text { for } \mathrm{J}=1,2 \ldots \ldots \ldots . \mathrm{s} .
\end{array}
\end{aligned}
$$

\section{Where,}

$\Theta_{1}$ is the scalarizing factor as arithmetic, geometric, harmonic, new arithmetic, new geometric and new harmonic averages of optimal values of the maximization objectives and

$\mathrm{\Theta}_{2}$ is the scalarizing factor as arithmetic, geometric, harmonic, new arithmetic, new geometric and new harmonic averages of optimal values of the minimization objectives.

\section{NUMERICAL EXAMPLE}

The following example used in the studies [3], [8] have been used by Sanjay and Adarsh.

$\operatorname{Max} \cdot Z_{1}=X_{1}+2 X_{2}$

$\operatorname{Max} . Z_{2}=X_{1}$

$\operatorname{Min} . Z_{3}=-2 X_{1}-3 X_{2}$

Min. $Z_{4}=-X_{2}$

\section{Subject to:}

$$
\begin{aligned}
6 \mathrm{X}_{1}+8 \mathrm{X}_{1} & \leq 48 \\
\mathrm{X}_{1}+\mathrm{X}_{2} & \geq 3 \\
\mathrm{X}_{1} & \leq 4 \\
\mathrm{X}_{2} & \leq 3 \\
\mathrm{X}_{1}, \mathrm{X}_{2} & \geq 0
\end{aligned}
$$

\section{SOLUTION}

\begin{tabular}{|c|c|c|c|c|}
\hline \multirow[t]{2}{*}{ Particular } & \multicolumn{4}{|c|}{ Individual Optimization } \\
\hline & $\operatorname{Max} . Z_{1}$ & $\operatorname{Max} . Z_{2}$ & Min. $Z_{3}$ & Min. $Z_{4}$ \\
\hline $\begin{array}{ll}\mathbf{X}_{1}, & \mathbf{X}_{2}\end{array}$ & 4, & 4, & $4, \quad 3$ & $4, \quad 3$ \\
\hline $\mathbf{Z}_{1}$ & 10 & 10 & 10 & 10 \\
\hline $\mathbf{Z}_{2}$ & 4 & 4 & 4 & 4 \\
\hline$\overline{Z_{3}}$ & -17 & -17 & -17 & -17 \\
\hline $\mathbf{Z}_{4}$ & -3 & -3 & -3 & -3 \\
\hline
\end{tabular}

The example was first solved for optimizing all the objectives individually. The solution is presented in table 1. All the four objectives have been optimized by a single solution. This reveals the absence of conflicts amongst objectives and therefore, the example is not suitable for using MOO techniques.
Table 1: Individual Optimization

This has been further reflected in the solution of multi-objective optimization presented in table 2. The solution of all the methods are unique with the values of decision variables $\mathrm{X}_{1}=4$ and $X_{2}=3$. The achievements of the basic objectives $Z_{1}, Z_{2}, Z_{3}$, and $Z_{4}$ are same as in the individual optimization.

Table 2: Solution of MOLPP after applying AHA simplex algorithm and Gauss Elimination Technique.

\begin{tabular}{|c|c|c|c|c|c|c|c|}
\hline $\begin{array}{c}\text { Ite } \\
\mathrm{m}\end{array}$ & $\begin{array}{c}\text { Chan } \\
\text { dra } \\
\text { Sen's } \\
\text { techn } \\
\text { ique }\end{array}$ & $\begin{array}{c}\text { Arith } \\
\text { metic } \\
\text { avera } \\
\text { ge } \\
\text { techn } \\
\text { ique }\end{array}$ & $\begin{array}{c}\text { Geom } \\
\text { etric } \\
\text { avera } \\
\text { ge } \\
\text { techn } \\
\text { ique }\end{array}$ & $\begin{array}{c}\text { Harm } \\
\text { onic } \\
\text { avera } \\
\text { ge } \\
\text { techn } \\
\text { ique }\end{array}$ & $\begin{array}{c}\text { New } \\
\text { arith } \\
\text { metic } \\
\text { avera } \\
\text { ge } \\
\text { techn } \\
\text { ique }\end{array}$ & $\begin{array}{c}\text { New } \\
\text { geom } \\
\text { etric } \\
\text { avera } \\
\text { ge } \\
\text { techn } \\
\text { ique }\end{array}$ & $\begin{array}{c}\text { New } \\
\text { harm } \\
\text { onic } \\
\text { avera } \\
\text { ge } \\
\text { techn } \\
\text { ique }\end{array}$ \\
\hline $\mathrm{X}_{1}, \mathrm{X}_{2}$ & 4,3 & 4,3 & 4,3 & 4,3 & 4,3 & 4,3 & 4,3 \\
\hline$Z_{1}$ & 10 & 10 & 10 & 10 & 10 & 10 & 10 \\
\hline$Z_{1}$ & 4 & 4 & 4 & 4 & 4 & 4 & 4 \\
\hline$Z_{1}$ & -17 & -17 & -17 & -17 & -17 & -17 & -17 \\
\hline$Z_{1}$ & -3 & -3 & -3 & -3 & -3 & -3 & -3 \\
\hline$Z^{*}$ & 3.9998 & 3.9999 & 5.0141 & 6.3710 & 9.7141 & 9.8150 & 9.9164 \\
\hline
\end{tabular}

$Z^{*}$ - Multi-objective function

The MOO techniques have been ranked according to the values of the multi-objective function which is not logical. The multi-objective functions have been formulated using different methods. Hence, the values of multi-objective functions should not be compared.

\section{SUMMARY}

It is clear from the analysis that proposed technique has not been formulated appropriately. The numerical example used was also not suitable. The solution has not been interpreted correctly.

\section{REFERENCES}

[1] Sanjay Jain and Adarsh Mangal (2020). Modeling of Gauss Elimination Technique and AHA Simplex Algorithm for Multi-objective Linear Programming Problems. Asian Journal of Probability and Statistics.8(4): 1-14.

[2] Sen, C. (1983). A new approach for multi-objective rural development panning. The Indian Economic Journal, Vol. 30(4), 91-96. 
[3] Sulaiman, N.A. and Hamadameen, Abdul-Qader O.(2008), Optimal Transformation Technique to Solve Multi-Objective Linear Programming Problem (MOLPP), Journal of Kirkuk University - Scientific Studies , Vol. 3 (2), 158-168.

[4] Sulaiman, N. A. and Abdulrahim, B. K. (2013) Using Transformation Technique To Solve Multi- Objective Linear Fractional Programming Problem. International Journal of Research and Reviews in Applied Sciences, Vol.14 (3), 559-567.

[5] Nejmaddin A. Sulaiman, Basiya K. Abulrahim (2013) Arithmetic Average Transformation Technique to Solve Multi-Objective Quadratic Programming Problem. Journal of Zankoy Sulaimani, 15(1), 57-69.

[6] Nejmaddin A. Sulaiman, Gulnar W. Sadiq \& Basiya K. Abdulrahim. (2014) New Arithmetic average

technique to solve Multi-Objective Linear FractionalProgramming: Problem and its comparison with other techniques. International Journal of Research and Reviews in Applied Sciences, Vol.18 (2) , 122-131.

[7] [Nejmaddin A. Sulaiman, Maher A. Nawkhass (2015)Using Short-Hierarchical Method to Solve Multi-Objective Linear Fractional Programming Problems. Journal of Garmian University, 1-15.

[8] Nejmaddin A. Sulaiman, Rebaz B. Mustafa, (2016) Using harmonic mean to solve multi-objective linear programming problems. American Journal of Operations Research, 6, 25-30.

[9] Nejmaddin A. Sulaiman, Ronak M. Abdullah and Snur O. Abdull (2016) Using Optimal Geometric Average Technique to Solve Extreme Point Multi-Objective Quadratic Programming Problems Journal of Zankoy Sulaimani, 18(3), 63-72.

[10] Akhtar Huma, Modi Geeta and Duraphe Sushma, (2017), Transforming and Optimizing Multi-Objective Quadratic Fractional Programming Problem. International Journal of Statistics and Applied Mathematics, Vol. 2, (1) 01-05.

[11] [Samsun Nahar, Md. Abdul Alim (2017) A New Statistical Averaging Method to Solve Multi-Objective Linear Programming Problem. International Journal of Science and Research. Vol. 6(8), 623-629.

[12] Akhtar, Huma, Geeta Modi and Sushma Duraphe (2017) An Appropriate Approach for Transforming and Optimizing Multi-Objective Quadratic Fractional Programming Problem. International Journal of Mathematics Trends and Technology Vol. 50 (2), 80-83.

[13] Samsun Nahar, Md. Abdul Alim (2017). A New Geometric Average Technique to Solve Multi-Objective Linear Fractional Programming Problem and Comparison with New Arithmetic Average Technique. IOSR Journal of Mathematics (IOSR-JM)Vol. 13, (3), 39-52.

[14] Zahidul Islam Sohag, Md. Asadujjaman (2018).A Proposed New Average Method for Solving Multi-Objective Linear Programming Problem Using Various Kinds of Mean Techniques. Mathematics Letters , 4(2): 25-33.

[15] Samsun Nahar, Samima Akther, Mohammad Abdul Alim (2018) Statistical Averaging Method and New Statistical Averaging Method for Solving Extreme Point Multi-Objective Linear Programming Problem, Mathematics Letters, 4(3): 44-50.

[16] S. Nahar and M. A. Alim , (2018).Weighted Sum Method for Making Single Objective from Multi-objective Linear Programming Problem (MOLPP) and Comparison with Chandra Sen's Method, (accepted) BSME conference (BUET) Dhaka, Dec. 19-21, 2018.

[17] Zahidul Islam Sohag, and M. Asadujjaman (2019) A Proposed Method for Solving Quasi-Concave Quadratic
Programming Problems by Multi-Objective Technique with Computer Algebra, IOSR Journal of Mathematics, Vol. 15,(1)12-18.

[18] Basiya K. Abdulrahim, Shorish O. Abdulla (2019). Using Interactive Techniques and New Geometric Average Techniques to Solve MOLFPP. Journal of University of Garmian, Vol. 6 (3), 375-382. https://doi.org/10.24271/garmian.196363.

[19] Chandra Sen (2018) Multi Objective Optimization Techniques: Misconceptions and Clarifications. International Journal of Scientific and Innovative Mathematical Research Vol. 6, Issue 6, 29-33.

[20] Chandra Sen (2018) Sen's Multi-Objective Programming Method and its Comparison with Other Techniques. American Journal of Operational Research,Vol. 8 (1): 10-13.

[21] Chandra Sen (2019) Improved Scalarizing Techniques for Solving Multi-Objective Optimization Problems. American Journal of Operational Research, Vol. 9 (1): 8-11.

[22] Chandra Sen (2020) Improved Averaging Techniques for Solving Multi-Objective Optimization (MOO) Problems. SN Applied Sciences.2: 286.

[23] Chandra Sen (2020) Sen's Multi Objective Optimization (MOO) Technique-An Extension. International Journal for Modern Trends in Science and Technology (IJMTST), Vol. 6 (9), 77-79.
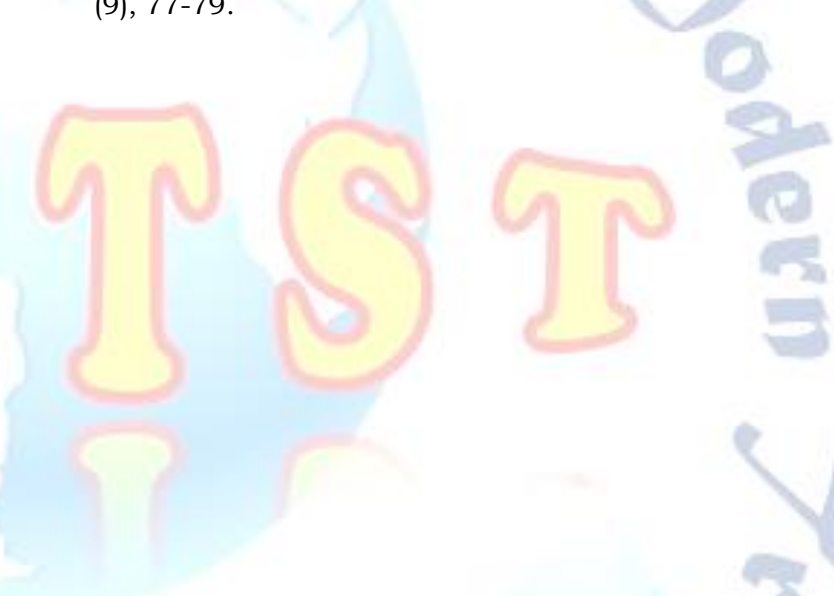